\title{
Study of the Linear Equation Heeling Angle Prediction by using Simulation Data
}

\author{
DongHyup Youn ${ }^{1, a, *}$, ChungHwan Park ${ }^{1, b}$ and NamKyun Im $^{2, c}$ \\ ${ }^{1}$ Marine Leisure Equipment Research Division, Research Institute of Medium \& Small \\ Shipbuilding, Busan, South Korea \\ ${ }^{2}$ Division of Navigation Information System, Mokpo National Maritime University, Mokpo, South \\ Korea \\ dhyoun@rims.re.kr,chpark@rims.re.kr,namkyun.im@mmu.ac.kr \\ *corresponding author
}

Keywords: Dangerous Time, Heeling Angle Prediction, Linear Equation, Ship Accident.

Abstract: As ships become bigger, faster, and diverse, the use of marine transportation increased the transportation. However, the number of ship accidents also increased. Ship accidents cause loss of life and property as well as environmental disasters. The occurrence of ship accidents causes enormous economic and environmental impacts. Especially, in case of passenger ships, methods for preventing ship accidents are being discussed to prevent losing numerous human lives. The purpose of this study is to provide basic data for evacuation before reaching the dangerous time by predicting the time to reach the risk of capsize based on the heeling angle of the passenger ship. Based on the sinking accident between 2012 and 2016, we set up specific scenarios and simulated the real-life data using commercial software MOSES V20. The simulation result is the heeling angle over time. We compared it with the simulation results using the linear equation. As a result of the comparison, a huge error was observed in the short time interval. Predicting the time of the equation reaching the hazardous angle was estimated in a similar fashion. It is expected that it will be possible to provide basic data for evacuation of human and ship by using nonlinear equations and improving the forecast's accuracy.

\section{Introduction}

The enlargement and speeding-up of ships and the diversification in kinds of ships has largely increased the weight of the marine transportation means among the transportation means. Concurrently, the occurrence of ship accidents has also increased. The occurrence of ship accidents causes not only loss of human life and property but also occurrence of environmental disasters, having an enormous economic and environmental impact. Especially, cruise ships cause large damage to humane life, so the methods to prevent ship accidents are being discussed.

Meanwhile, damage to the hull brings a slow change in water plane and a faster motion in hull response via ocean waves. The ships get to be subjected to loads due to very complicated flows such as internal flows generated by flooding in the hull as well as incident waves, and scattered waves and radiation waves depending on a change in positions of ships. Accordingly, the damaged 
ship may capsize or sink because its dynamic stability is not guaranteed, and may sink because the damage to its hull continues via complicated wave loads although its damage stability is guaranteed.

Many studies have been conducted via analysis of six-degree of freedom hull motions and threedimensional wave loads by assuming a damaged and flooded part of hull [1-3], and a water tank experiment showed that symmetric damage affected the motion response to increase the natural frequency of the ship a little [4]. A study on the ship motion characteristics due to flooding in the compartment was also conducted in a time domain [5]. However, the above study in a time domain investigated the characteristics of motion through damage to a particular position rather than predicting up to the domain that the ship became at risk finally. In addition, the characteristics of motion considering the internal flow characteristics due to damage to a particular position considering the internal flow characteristics due to damage to a particular position were analyzed and even a study on the damage stability was conducted.

This study aimed to provide basic data to evacuate people before arriving at a risk time by predicting the time taken to a risk of capsizing based on the heeling angle of a cruise ship. This study aimed to predict the remaining time up to a particular heeling angle at a past time on the premise that the heeling continued to happen, not on the condition that the ship found damage stability after heeling, when the hull was damaged.

The chapter 2 described theories, ship specifications, modeling methods and numerical analysis methods, the chapter 3 described the results of numerical analysis, the chapter 4 described the prediction of a particular heeling angle time through numerical analysis, and the chapter 5 made a conclusion.

\section{Theory of Ship and Numerical Method}

\subsection{Equations of ship motion}

For the mathematical descriptions of fluid and body motions, a body fixed coordinates system is adopted. By introduction the centre of rotation, the body motions are able to be described with respect to a translated coordinates system (and shown in Figure. 1)

The wave height and steepness are also assumed to be small so that the linear wave theory may be used. The fluid is assumed to be incompressible and inviscid, and the flow be irrotational. Thus the flow field can be described by the gradient of a velocity potential, which is governed by the Laplace equation and at the same time it should satisfy the proper boundary conditions. The body is rigid and in a state of stable equilibrium when in calmwater. By considering the hydrodynamic forces acting on the body, the equations of motion are obtained in the form

$$
\begin{gathered}
\sum_{j=1}^{6} x_{j}\left[-\omega^{2}\left(M_{i j}+A_{i j}-i \omega\left(B_{i j}+B_{i j}^{v}\right)+\left(C_{i j}+K_{i j}\right)\right]=F_{i}\right. \\
\alpha+\beta=\chi .
\end{gathered}
$$

Where Bijv is the viscous damping matrix. Cij and Kij are hydrostatic restoring and external mooring stiffness matrix, respectively. 


\subsection{Characteristics of the selected ship}

Table I shows the main particulars of the ship, which has been studied extensively in the ITTC benchmark studies, as reported by The Specialist Committee on Prediction of Extreme Ship Motions and Capsizing [4] and Papanikolaou and Spanos[6].

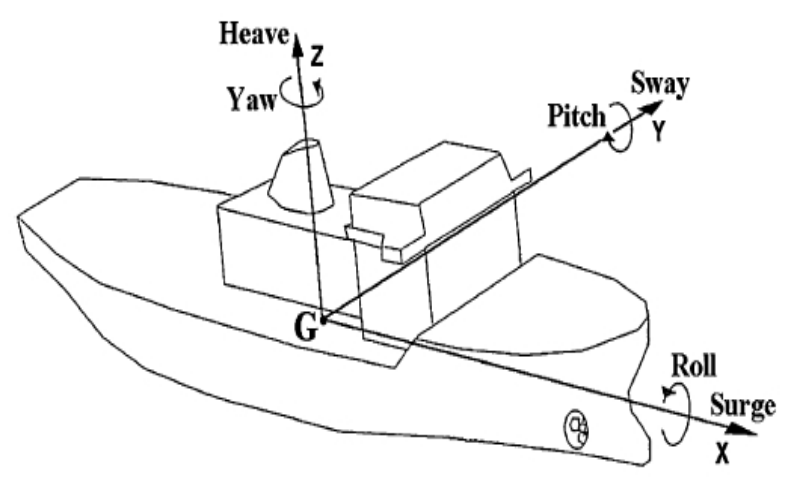

Figure 1: Coordinate system for ship motions

Figure. 2 shows the body plan of the selected passenger Ro-Ro ship, known in the literature as PRR1. The hull features a small bulb at the bow and substantial flare in the bow and stern sections.

Figure. 3 shows the compartments to be flooded (shaded) in this study, which are composed of compartment 9 (tail), 10 and 11, considering only flooding of the starboard.

In addition, a wrecked hole was set to happen at the bottom of the compartment 9 so that water could enter the neighboring compartments from the highest part ( $5 \mathrm{~m}$ above the bottom) of the compartment 9. The size of the wrecked hole and the hole size between compartments are shown in Table II based on the sinking accident between 2012 and 2016.

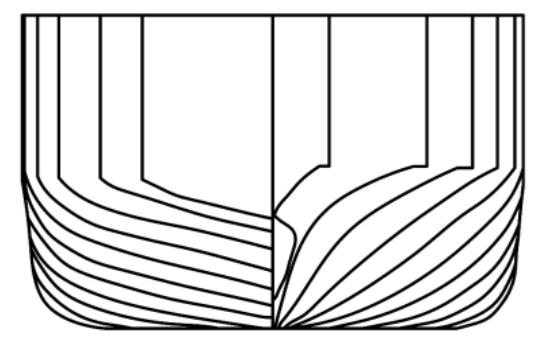

Figure 2: Body plan of passenger Ro-Ro ship PRR1 (from The Specialist Committee on Prediction of Extreme Ship Motions and Capsizing [4]) 
Table 1: Main Particulars of Passenger Ro-Ro-ship PRR1

\begin{tabular}{|l|l|l|}
\hline \multicolumn{1}{|c|}{ Dimensions } & Unit & \multicolumn{1}{c|}{ Value } \\
\hline Displacement, $\Delta$ & ton & 17268.0 \\
\hline Length between perpendiculars, $\mathrm{L}_{\mathrm{pp}}$ & $\mathrm{m}$ & 170.00 \\
\hline Breadth, $\mathrm{B}$ & $\mathrm{m}$ & 27.80 \\
\hline Depth to the main deck, $\mathrm{D}_{\mathrm{md}}$ & $\mathrm{m}$ & 9.40 \\
\hline Depth to the upper deck, $\mathrm{D}_{\mathrm{ud}}$ & $\mathrm{m}$ & 17.78 \\
\hline Draught, $\mathrm{T}$ & $\mathrm{m}$ & 6.25 \\
\hline Metacentric height, $\mathrm{GM}$ & $\mathrm{m}$ & 2.63 \\
\hline Roll natural periods, $\mathrm{T}_{\mathrm{s}}$ & $\mathrm{s}$ & 13.00 \\
\hline
\end{tabular}
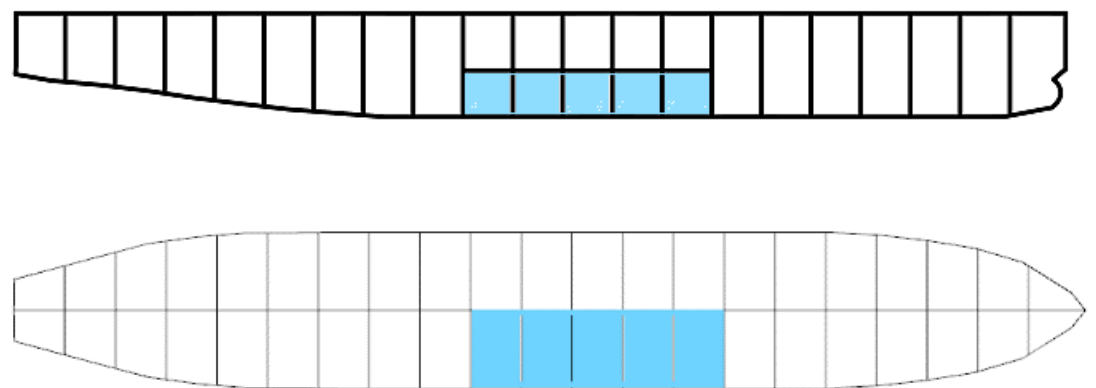

Figure 3: Vessel's compartmentation below car deck and studied damage case

Table 2: Information of Wrecked Hole and Connect Hole

\begin{tabular}{|l|c|c|}
\hline \multicolumn{1}{|c|}{ Measurement } & Unit & Value \\
\hline Position of wrecked hole & $\mathrm{m}$ & $80,11,2$ \\
\hline Size of wrecked hole(diameter) & $\mathrm{m}$ & 0.2 \\
\hline Type of wrecked hole & - & Circle \\
\hline Position of connect hole & $\mathrm{m}$ & $78.155,8,5$ \\
\hline Size of connect hole(diameter) & $\mathrm{m}$ & 0.2 \\
\hline
\end{tabular}

Table 3: Sea State Characteristics

\begin{tabular}{|l|l|c|l|}
\hline Number & Wave height (m) & Wind speed (m/s) & Characteristics \\
\hline 0 & 0 & 0.7717 & Calm(glassy) \\
\hline 1 & $0-0.1$ & 2.5722 & Calm(rippled) \\
\hline 2 & $0.1-0.5$ & 4.3728 & Smooth(wavelets) \\
\hline 3 & $0.5-1.25$ & 6.945 & Slight \\
\hline 4 & $1.25-25$. & 9.774 & Moderate \\
\hline 5 & $2.5-4$ & 12.6039 & Rough \\
\hline 6 & $4-6$ & 19.2917 & Very rough \\
\hline 7 & $6-9$ & 26.4939 & High \\
\hline 8 & $9-14$ & 30.6094 & Very high \\
\hline 9 & Over 14 & 32.9244 & Phenomenal \\
\hline
\end{tabular}




\subsection{Numerical analysis method}

For numerical analysis, commercial software MOSES 7.10 V8 was used. MOSES can conduct an analysis through strip theory and $3 \mathrm{~d}$ diffraction theory by modeling hulls and compartments. The $3 \mathrm{~d}$ diffraction theory is a potential theory to need modeling of the whole ship, however raising the accuracy of numerical analysis more than strip theory, so the $3 \mathrm{~d}$ diffraction theory was used. For the sea state, a real sea state was assumed, and the Table 3 shows the sea state by step. The spectrum is used the Bretschneider spectrum. The Bretschneider spectrum is defined below:

$$
\begin{gathered}
S_{B}(\omega)=\frac{A}{\omega^{5}} \exp \left(\frac{-B}{\omega^{4}}\right) \\
\alpha+\beta=\chi .
\end{gathered}
$$

Where,

$$
\begin{gathered}
A=172.75 \frac{H_{c h a r}^{2}}{T^{4}}, B=\frac{691}{T^{4}} \\
\alpha+\beta=\chi .
\end{gathered}
$$

The two parameters are the characteristic wave height, Hchar, and the average period, T.

\section{Numerical Results}

\subsection{Motions of the ship}

The natural period of PRR1 was 13 seconds, and the result for gyration of inertia was derived via a roll decay test. GM was set to $2.63 \mathrm{~m}$, and the damping coefficient was 0.75 .

Figure. 4 shows a roll decay curve, which was compared with the experimental data in a reference, and the numerical analysis shows 12.9 seconds, which is almost similar, although they don't perfect coincide.

Figure. 5 shows the result of roll response amplitude operator(RAO's), which shows a peak value at a similar point to the experimental data in the reference.

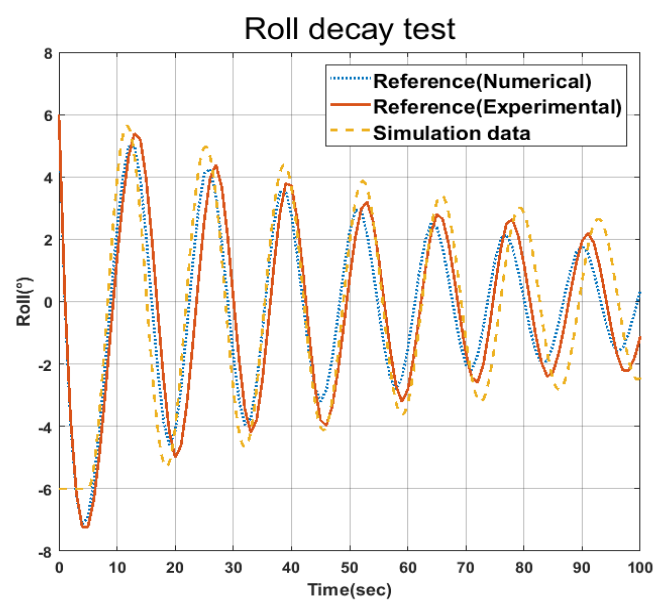

Figure 4: Roll decay test (includes results from study of damaged ship motions taking into account floodwater dynamics [4]) 


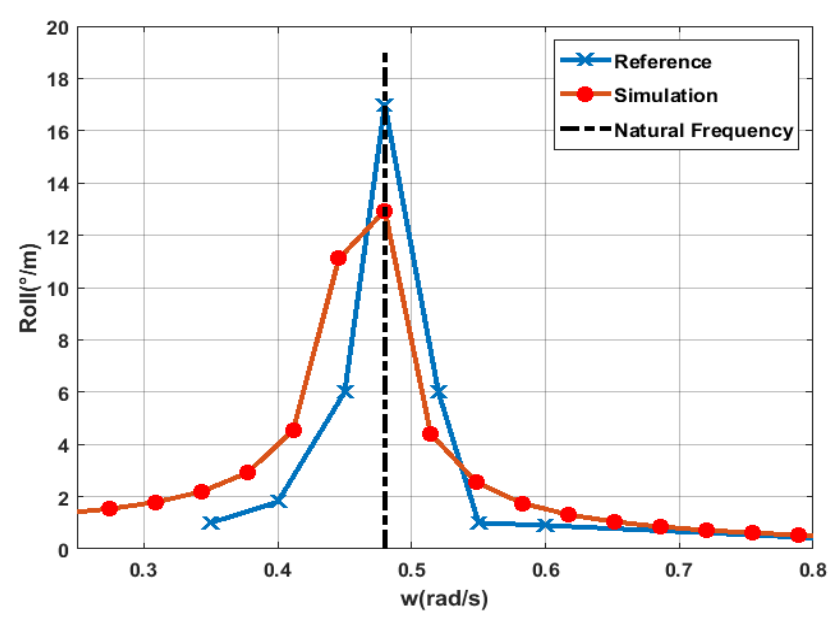

Figure 5: Roll motion response amplitude operator (includes results from the Specialist Committee on Prediction of Extreme Ship Motions and Capsizing[4])

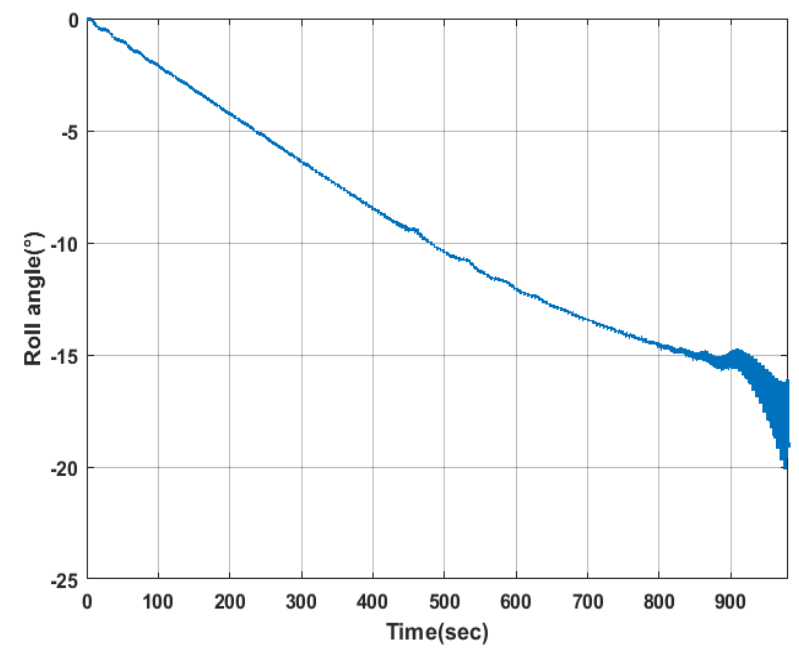

Figure 6: Result of time domain analysis

\subsection{Result of time domain analysis}

For analysis in a time domain, the time taken to a particular heeling angle was analyzed numerically for a case in which the ship was damaged. Figure. 6 shows its results. The final taken time was 980s, which was measured with the time that a particular heeling angle was reached for the first time. The heeling angle increased nonlinearly rather than linearly, having a nonlinear feature as the angle increased. Therefore, if a ship was damaged, a slow heeling angle happens initially, and after a certain point of time, a rapid heeling angle happens.

\section{Heeling Angle Prediction Method and Result}

The heeling angle was measured based on the simulation results. The time taken to a particular heeling angle $\left(20^{\circ}\right)$ was calculated in a linear equation using the time taken from the initial heeling angle $\left(5^{\circ}\right)$ to the second heeling angle, whose results are shown in Table 4 . As the angle range from the initial heeling angle $\left(5^{\circ}\right)$ to the second heeling angle increases, the prediction of the time taken 
to a particular heeling angle seems to be relatively correct. In addition, even though the angle range from the initial heeling angle to the second heeling angle increases, as the angle approaches a particular heeling angle, the time appears to be linear, and the heeling angle in the real simulation result appears to be nonlinear, not linear.

Table 4: Predicition Time to $20^{\circ}$ from $5^{\circ}$ Using Time Slope

\begin{tabular}{|c|c|c|c|c|c|}
\hline Angle $\left.\mathbf{(}^{\circ}\right)$ & $\begin{array}{c}\text { Time } \\
(\mathbf{s e c})\end{array}$ & From 5 & Slope & $\begin{array}{c}\text { Prediction time at } \\
\mathbf{2 0}^{\circ}(\mathbf{s e c})\end{array}$ & Error \\
\hline 5 & 235.2 & 0.0 & 0.0 & 0.0 & 0.00 \\
\hline 7 & 328.8 & 93.6 & 4638 & 936.0 & 4.49 \\
\hline 9 & 427.2 & 192.0 & 48 & 960.0 & 2.04 \\
\hline 11 & 539.2 & 304.0 & 50.6 & 1013.3 & 3.40 \\
\hline 13 & 666.4 & 431.2 & 53.9 & 1078.0 & 10.00 \\
\hline 15 & 842.0 & 606.8 & 60.7 & 1213.6 & 23.84 \\
\hline 17 & 946.0 & 710.8 & 59.2 & 1184.7 & 20.89 \\
\hline 20 & 980.0 & 744.8 & 0 & 980.0 & 0.00 \\
\hline
\end{tabular}

\section{Conclusion}

This study was conducted as an initial stage of study to predict the time taken to a risk of capsizing based on the heeling angle of a cruise ship. The results of study can be summarized as follows.

A simulation was conducted for PPR1, and as a result of analysis in a time domain by setting the conditions of the wrecked hole and the conditions of the ocean, the heeling angle increased rapidly initially, but the heeling angle increased slowly after a certain point of time.

The time taken to a particular heeling angle was linearly predicted through a heeling angle prediction method, and as the angle range from the initial heeling angle to the second heeling angle was larger the time taken to a particular heeling angle was predicted more accurately. In addition, it was noticed that using an angle range around a particular heeling angle resulted in a more accurate prediction.

This study conducted a prediction via a linear equation, so it can be used as initial data to predict the time that particular heeling happens. However, as the simulation result, the heeling angle increased slowly after a particular time after occurrence of heeling nonlinearly rather than linearly. Accordingly, an additional study having universality is necessary by deriving an equation on nonlinearity and then deriving an empirical formula based on various simulations and real data.

\section{Acknowledgment}

This research was a part of the projects entitled "Development of Ship-handling and Passenger Evacuation Support System" funded by the Ministry of Oceans and Fisheries, Korea.

\section{References}

[1] J.T. Dillingham, "Motion studies of a vessel with water on deck," Ma Tecnol vol. 18(1), pp. 38-50, 1981.

[2] T.A. Santos, C. Guedes Soares, "Investigation into the effects of shallow water on deck in ship motion," Proceedings of the 8th international conference on the stability of ships and ocean vehicles, 2003, pp. 81-96.

[3] T.A. Santos, C. Guedes Soares, "Study of damaged ship motions taking into account floodwater dynamics," Journal of Marine Science and Technology, vol. 13, pp. 291-307, August 2008.

[4] The Specialist Committee on Prediction of Extreme Ship Motions and Capsizing (Chaired by D. Vassalos), "Final report and recommendations to the 23rd ITTC," Proceedings of the 23rd international towing tank conference, 2002, pp. 625-641 
[5] T.A. Santos, I.E. Winkle, C. Guedes Soares, "Time domain modelling of the transient asymmetric flooding of ro-ro ships," Ocean Engneering, vol 29, pp. 667-688, 2002.

[6] D. Spanos, A. Papanikolaou, "On the modelling of flooding water dynamics and its effects on ship motions," Proceedings of the 6th international ship stability workshop, 2002. 